\title{
Components of physical capacity in patients with chronic obstructive pulmonary disease: relationship with phenotypic expression
}

This article was published in the following Dove Press journal: International Journal of Chronic Obstructive Pulmonary Disease 25 January 2011

Number of times this article has been viewed

\author{
Eduardo Márquez-Martín' \\ Pilar Cejudo Ramos' \\ José Luis López-Campos' \\ María del Pilar Serrano \\ Gotarredona $^{2}$ \\ Silvia Navarro Herrero ${ }^{2}$ \\ Rodrigo Tallón Aguilar' \\ Emilia Barrot Cortes' \\ Francisco Ortega Ruiz' \\ 'Medical-Surgical Unit of \\ Respiratory Diseases, University \\ Hospital Virgen del Rocío, Seville, \\ Spain; ${ }^{2}$ Radiodiagnostic Unit, \\ University Hospital Virgen del \\ Rocío, Seville, Spain
}

Background: More accurate phenotyping of COPD is of great interest since it may have prognostic and therapeutic consequences. We attempted to explore the possible relationship between the extent of emphysema, as assessed by high-resolution computed tomography (HRCT), and COPD severity. We also included some study variables involving exercise tolerance evaluation and peripheral muscle strength (PMS) measurement.

Methods: Sixty-four patients with COPD (mean age $64 \pm 7$ years) were enrolled in a prospective observational cross-sectional study. All patients underwent clinical and functional evaluations: assessment of dyspnea, body mass index (BMI), health status assessment, spirometry testing, and arterial blood gas analysis. The extent of emphysema was graded using HRCT. Functional capacity was evaluated by a cardiopulmonary maximal exercise testing (CPET), the shuttle walking test, and by estimation of PMS.

Results: Half of the study patients had an emphysematous phenotype. There was a significant correlation between the score derived from analysis of HRCT images and BMI and respiratory functional parameters, as well as $\mathrm{VO}_{2}$ max (maximal oxygen uptake) and chest pull 1RM (1 rep max). Compared with subjects with a nonemphysematous phenotype, those with an emphysematous phenotype showed a lower BMI, a reduced PMS, and displayed a lower power at CPET. Significant differences in lung function tests were found for diffusing capacity and hyperinflation. No significant differences in quality of life were observed between the two study groups.

Conclusions: Compared with subjects with a nonemphysematous phenotype, subjects with an emphysematous phenotype has a different profile in terms of BMI, lung function, PMS, and exercise capacity.

Keywords: chronic obstructive pulmonary disease, exercise tolerance, emphysema, phenotypes, lung function

\section{Introduction}

Chronic obstructive pulmonary disease (COPD) is a disease state characterized by airflow limitation that is not fully reversible and usually progressive. ${ }^{1}$ This airflow limitation may be caused by both inflammation and wall thickening in small airways, which is responsible for the narrowing of the airway lumens, and in some but not all cases, parenchymal destruction of the lungs (emphysema), leading to loss of the elastic lung recoil. ${ }^{2}$ Traditionally, on the basis of determined clinical, functional, and radiologic features, patients with COPD used to be classified into 2 different biotypes: the "blue boater", in association with a predominant chronic bronchitis condition, and the "pink puffer", identified as predominant emphysema. ${ }^{3}$ However these are only the
Correspondence: Eduardo Márquez-Martín Medical-Surgical Unit of Respiratory Diseases, University Hospital Virgen del Rocío, Seville, Spain

$\mathrm{Tel}+34955013164$

Fax +34955013167

Email eduardo.marquez.sspa@

juntadeandalucia.es 
two extreme phenotypes among the broad variety of clinical presentations in COPD.

Studies conducted in recent years have revealed that patients with the same stage of disease may offer different pathological changes, ${ }^{4-6}$ and classic COPD phenotypes clearly differ from these based on severity of emphysema as assessed by high resolution computed tomography (HRCT) scanning. 4

Based on studies with HRCT support, some authors find that patients with the phenotype in which emphysema predominates have more severe lung function impairment but more intense airway inflammation and a higher BODE index (body mass index, airflow obstruction, dyspnea, exercise capacity) and subsequently, a possible more serious systemic dysfunction. ${ }^{7}$ In contrast, other studies show that the severity of emphysema is highly variable even among subjects with the same functional stage of COPD, which does not support emphysema as the major cause of airflow limitation in COPD. ${ }^{4}$

In COPD patients, health-status measurement and the BODE score predicts mortality better than $\mathrm{FEV}_{1}$ (forced expiratory volume in the first second of expiration) since $\mathrm{FEV}_{1}$ is a component of BODE. ${ }^{8,9}$ These multidimensional tools may be more valuable because they can reflect the systemic nature of the disease. Other parameters, such as physical activity and exercise tolerance as measured by cycle ergometry, have been demonstrated to be strong independent predictors of COPD mortality. ${ }^{10,11}$ In addition, peripheral muscle strength ${ }^{12}$ and muscle mass depletion, ${ }^{13}$ which do reflect the skeletal muscle dysfunction present in COPD patients, also offer prognostic information. Some authors state that these comorbid manifestations are more frequent in patients with predominant emphysema, what would imply a poorer prognosis. ${ }^{14}$

Consequently more accurate phenotyping of COPD is of great interest since it may have prognostic and therapeutic consequences. We attempt to explore the possible relationship between emphysema extension as assessed by HRCT, and COPD severity. Our hypothesis is that patients with predominant emphysema have a greater systemic dysfunction, and then show evidence of lower exercise capacity and peripheral muscle strength than those with COPD not associated with emphysema. To clarify the differences between the morphological phenotypes and clinical features of COPD, we classified patients into 2 phenotypes according to the dominance of emphysema on chest HRCT and examined the clinical characteristics, including exercise and muscle function, in each phenotype.

\section{Material and methods}

\section{Study participants}

Sixty-four male patients with age-related COPD were enrolled in a prospective, observational, cross-sectional study. The study was approved by the Institutional Review Board and written informed consent was obtained from all participants. Patients were recruited from the outpatient clinic. Inclusion criteria were: 1) being an adult patient with a diagnosis of COPD according to international guidelines, ${ }^{9}$ and 2) being clinically stable during the previous 3 months. The exclusion criteria were: 1) unwillingness to participate in the study, 2) a history of recent exacerbation ( $<3$ months) requiring systemic corticosteroids or antibiotics, and 3 ) any contraindication or inability to perform the study tests. ${ }^{15}$

All patients underwent clinical and functional evaluations that included assessment of dyspnea, body mass index (BMI), ${ }^{16}$ health status assessment, spirometry testing, and arterial blood gas analysis. These were followed by assessments of physical function and radiological examinations consisting of HRCT scans. The functional capacity of the study participants was evaluated by cardiopulmonary maximal exercise testing (CPET), the shuttle walking test (SWT), ${ }^{17}$ and by estimation of peripheral muscle strength (PMS).

\section{Dyspnea scale}

Basal dyspnea was measured using the modified Medical Research Council scale (mMRC) ${ }^{18}$ which classifies the degree of dyspnea ranging from 0 to 4 .

\section{Pulmonary function tests}

Spirography was performed using a pneumotachograph spirograph (Masterlab, Erich Jaeger GMBH, Wuerzburg, Germany) following the SEPAR ${ }^{19}$ and the ATS ${ }^{20}$ recommendations. Static lung volumes were determined plethysmographically. ${ }^{21}$ Arterial blood gas analysis was carried out according to the SEPAR ${ }^{22}$ recommendations.

\section{Health-related quality of life}

For the assessment of quality of life, we used a specific questionnaire for patients with COPD, the Chronic Respiratory Disease Questionnaire (CRDQ) proposed by Guyatt, which has been previously validated and translated into Spanish. ${ }^{23}$ It consists of 20 items rated from 1 to 7 (so that the higher the score better quality of life) and divided into 4 sections: dyspnea (questions $4 \mathrm{a}-4 \mathrm{e}$ ), fatigue (questions $7,10,14,16$ ), emotional functioning (questions 5, 8, 11, 13, 15, 17, 19), and mastery (questions 6, 9, 12, 18). Normal range should be the maximum amount for all items, which means 7 points 
in each section and 28 in total (the maximum amount of the 4 sections). The changes are considered clinically significant when the score for each question increased by at least 0.5 points on the overall score for each of the paragraphs (0.5-1: slight change; $1-1.5$ : moderate; $\geq 1.5$ : excellent).

\section{Peripheral muscle strength}

Weight-lifting capacity was measured as the heaviest weight that could be lifted once throughout the complete range of movement (1RM test, 1 rep max test). ${ }^{24}$ Typical PMS values were described by Hamilton et al. ${ }^{25}$

\section{Shuttle walking test}

The SWT was conducted as described by Singh et al, ${ }^{26}$ which requires patients to walk a $10 \mathrm{~m}$ course marked out by 2 cones with progressive levels. The maximum distance to walk is $1020 \mathrm{~m}$.

\section{Maximal cardiopulmonary exercise test}

Maximal cardiopulmonary exercise testing was performed on a cycle ergometer (Collins Respiratory Ergomed, USA) according to international standards. ${ }^{15,27}$ Typical values were described by Wasserman et al. ${ }^{28}$ The following variables were measured: oxygen consumption; carbon dioxide production; an indirect assessment of anaerobic threshold, and the respiratory pattern (maximal breathing capacity, tidal volume, respiratory rate). ${ }^{29}$ The exercise was performed on electrocardiographic, heart rate and pulsioxymetric monitoring. All measurements were integrated into the cycle ergometer device (Collins Respiratory Ergomed, USA) and evaluated simultaneously during the test. After the exercise, we assessed heart rate, blood pressure, leg fatigue, chest pain, and dyspnea using the modified Borg's scale. ${ }^{30}$

\section{High-resolution computed tomography}

HRCT was used to distinguish between emphysematous and non-emphysematous phenotypes. Acquisition parameters were as follows: $1 \mathrm{~mm}$ collimation, 120 to $140 \mathrm{kV}, 75$ to $350 \mathrm{~mA}, 0.75$ to 1 seconds scanning time, and field of view 350 to $400 \mathrm{~mm}$. HRCT images were selected at 3 levels, including the aortic arch, the main carina, and 1 to $2 \mathrm{~cm}$ above the highest hemi-diaphragm. A window level of -700 to -900 Hounsfield units (HU) with a 600 to $1600 \mathrm{HU}$ window width were used for image interpretation. ${ }^{31}$ Two readers visually and independently assessed the severity of emphysema according to a modified scoring system adopted from previous studies with no knowledge of the patients' clinical information. ${ }^{32}$ We analyzed 6 images in 3 slices in the lungs; the total score from all images was considered as a representative value of the severity of emphysema in each person. Each image was classified as normal (score 0), up to $25 \%$ affected (score 1 ), up to $50 \%$ affected (score 2 ), up to $75 \%$ affected (score 3 ), and more than $75 \%$ affected (score 4 ), giving a minimum score of 0 and maximum of 24. Disagreement between the two radiologists was resolved by consensus. Emphysema was defined as the presence of a score $>6$, which means $25 \%$ of total area, according to Nakano et al. ${ }^{33}$

\section{Data analysis}

Quantitative variables were summarized with means and standard deviations. For descriptive purposes, variables are presented first for the entire study sample and thereafter according to the GOLD stages. ${ }^{1}$ Differences across different GOLD stages were assessed on the basis of analysis of variance (ANOVA). Qualitative variables were compared between emphysematous and nonemphysematous patients using the chi-square test. The correlation between the study variables was estimated using Pearson's correlation coefficient $(r)$. Quantitative variables were compared by Student's $t$ test. Data were analyzed by SPSS (SPSS Inc., Chicago IL, USA), version 14.0.

\section{Results}

Clinical and functional characteristics of the 64 patients are described in Table 1. Globally, our patients had a severe obstruction, hyperinflation, and hypoxemia. They had a mildly impaired pulmonary diffusion, and showed decreased exercise capacity and low HRQL and dyspnea indexes.

From the analysis of the HRCT images, we obtained scores ranging between 0 and 24 points. Based on these scores, half of the study participants $(n=32)$ were classified as emphysematous phenotype and half ( $n=32$ ) as nonemphysematous phenotype; median score for the whole group was $8.5 \pm 6.05$ points. By groups, emphysematous patients' score was significantly higher than that of nonemphysematous patients $(12.4 \pm 5.1$ vs $4.65 \pm 4.075$ points; $P<0.05)$. The mean attenuation values for the emphysema and nonemphysema groups were -889 (32.3) HU and -865 (25) HU, respectively. The correlation study (Table 2) showed a significant relation between the HRTC score and BMI, dyspnea indexes, respiratory function parameters, $\mathrm{VO}_{2} \max$ (maximal oxygen uptake), and chest pull 1RM.

When we separated patients into GOLD stages (Table 3), they were homogeneously distributed across the study groups. Patients with GOLD stages I and II were grouped 
Table I Baseline characteristics of the 64 male study participants

\begin{tabular}{|c|c|}
\hline Parameter & Mean \pm SD or $\%$ \\
\hline Age, yr & $64 \pm 7$ \\
\hline $\mathrm{BMI}, \mathrm{kg} / \mathrm{m}^{2}$ & $29 \pm 5$ \\
\hline CRDQ dyspnea & $2.8 \pm 0.7$ \\
\hline CRDQ fatigue & $4.2 \pm 0.9$ \\
\hline CRDQ emotional function & $4.7 \pm 0.9$ \\
\hline CRDQ mastery & $4.9 \pm 1.2$ \\
\hline CRDQ total & $16.7 \pm 2.9$ \\
\hline $\mathrm{FEV}_{1} \%$ predicted & $42 \pm 12$ \\
\hline TLC $\%$ predicted & $110 \pm 15$ \\
\hline RV \% predicted & $158 \pm 37$ \\
\hline KCO \% predicted & $84 \pm 28$ \\
\hline $\mathrm{PaO}_{2}, \mathrm{mmHg}$ & $72 \pm 11$ \\
\hline $\mathrm{PaCO}_{2}, \mathrm{mmHg}$ & $42 \pm 5.5$ \\
\hline CPET power, $\mathrm{W}$ & $61 \pm 25$ \\
\hline $\mathrm{VO}_{2} \max , \mathrm{mL} / \mathrm{min} / \mathrm{kg}$ & $14.5 \pm 3.7$ \\
\hline PMS neck press, kg & $24 \pm 6.5$ \\
\hline PMS chest pull, kg & $42 \pm 9.1$ \\
\hline PMS butterfly, $\mathrm{kg}$ & $19 \pm 6.8$ \\
\hline PMS flexion, kg & $16.7 \pm 6$ \\
\hline PMS extension, kg & $39 \pm 11.7$ \\
\hline SWT, m & $380 \pm 147$ \\
\hline
\end{tabular}

Abbreviations: $\mathrm{BMI}$, body mass index; $\mathrm{CRDQ}$, chronic respiratory disease questionnaire; $\mathrm{FEV}$, , forced expiratory volume in the first second of expiration; $\mathrm{TLC}$, total lung capacity; RV, residual volume; $\mathrm{KCO}$, Krogh coefficient; $\mathrm{PaO}_{2}$, arterial oxygen partial pressure at rest; $\mathrm{PaCO}_{2}$, arterial carbon dioxide partial pressure at rest; CPET, cardio-pulmonary exercise test; $\mathrm{VO}_{2}$ max, maximal oxygen uptake; PMS, peripheral muscle strength; SWT, shuttle walking test.

together since only 1 patient had stage I disease. Our results showed that the presence of emphysema is roughly equal across all levels of obstruction. PMS was similar in the three groups, but increasing GOLD stages were associated with a worsening of exercise capacity.

We differentiated COPD phenotypes according to HRCT findings (Table 4). Compared with nonemphysematous patients, emphysematous patients had a lower

Table 2 Significant relationships between HRCT emphysema score and clinical variables in patients with COPD

\begin{tabular}{lll}
\hline Clinical variable & $\boldsymbol{r}$ value & $\boldsymbol{P}$ value \\
\hline Dyspnea, mMRC & 0.282 & 0.028 \\
$\mathrm{BMI}, \mathrm{kg} / \mathrm{m}^{2}$ & -0.4 & $0.00 \mathrm{I}$ \\
$\mathrm{PaCO}, \mathrm{mmHg}$ & -0.346 & $0.0 \mathrm{I}$ \\
$\mathrm{IRM}$ chest pull, $\mathrm{kg}$ & 0.3 & 0.032 \\
$\mathrm{VO}_{2} \mathrm{max}, \mathrm{mL} / \mathrm{min} / \mathrm{kg}$ & -0.274 & 0.03 \\
$\mathrm{FVC}, \%$ & 0.346 & $0.0 \mathrm{I}$ \\
$\mathrm{FEV} / \mathrm{FVC}, \%$ & $-0.43 \mathrm{I}$ & $0.00 \mathrm{I}$ \\
$\mathrm{TLC}, \%$ & 0.5 & $0.00 \mathrm{I}$ \\
\hline
\end{tabular}

Abbreviations: $\mathrm{BMI}$, body mass index; $\mathrm{PaCO}_{2}$, arterial carbon dioxide partial pressure; FVC, forced vital capacity; FEV , forced expiratory volume in the first second of expiration; TLC, total lung capacity; KCO, Krogh coefficient; mMRC, modified Medical Research Council; IRM, I rep max; $\mathrm{VO}_{2}$ max, maximal oxygen uptake.
BMI (26.5 [3.5] vs 31.4 [5.2]; $P<0.001$ ), a reduced PMS (Figure 1), and displayed a significantly lower power at CPET (54 [21.5] vs 67.9 [26.7] W; $P<0.05$ ) (Figure 2). Both groups reached a similar distance in the SWT and there were no significant differences in HRQL indexes. It is important to note that because the grade of obstruction was not associated with a determined phenotype, both groups had a similar $\mathrm{FEV}_{1}$. Emphysematous patients showed a lower $\mathrm{CO}$ diffusion, lower $\mathrm{FEV}_{1} / \mathrm{FVC}$ ratio, and higher $\mathrm{FVC}$, functional residual capacity (FRC), and total lung capacity (TLC) than nonemphysematous patients (Table 4).

\section{Discussion}

In this study, we have provided evidence that patients with an emphysematous phenotype have a different profile in terms of BMI, some measures of lung function, PMS, and exercise tolerance compared with nonemphysematous phenotype patients. Although lung function is required to diagnose COPD and classify its severity, $\mathrm{FEV}_{1}$ values are not generally associated with symptom intensity or exercise capacity. ${ }^{34}$ Moreover, the usefulness of $\mathrm{FEV}_{1}$ as a prognostic factor for clinical outcomes and mortality in COPD has been questioned. Accordingly, numerous other factors including dyspnea or acute exacerbations have been shown to significantly affect survival. ${ }^{35,36}$ In recent years, there has been growing interest for patient-related outcomes in subjects with COPD, including clinical symptoms, the number of acute exacerbations, exercise tolerance, functional ability, and general well-being. ${ }^{37,38}$

Recent evidence has shown that different COPD phenotypes may be significantly associated with differences in BMI, health-related HRQL, ${ }^{4}$ small airway obstruction, ${ }^{39}$ responsiveness to bronchodilators, ${ }^{5}$ and systemic inflammation. ${ }^{40}$ To our knowledge, however, there is a paucity of information on the differences in physical function between emphysematous and nonemphysematous COPD patients.

Some authors have found no clinical or pulmonary functional differences between emphysematous and nonemphysematous patients. ${ }^{41}$ Other authors describe that patients with the phenotype in which emphysema predominates in HRCT are characterized by a severe pulmonary functional affect and a high airway inflammation. ${ }^{7}$ In our results, the severity of the emphysema varies even in patients with the same level of COPD. The grade of obstruction is not associated with a determined phenotype as both groups showed a similar $\mathrm{FEV}_{1}$. Emphysematous patients had lower CO diffusion, 
Table 3 Clinical and functional characteristics of the 64 male study participants

\begin{tabular}{|c|c|c|c|c|}
\hline Characteristics & $\begin{array}{l}\text { GOLD I-II } \\
(n=18)\end{array}$ & $\begin{array}{l}\text { GOLD III } \\
(n=29)\end{array}$ & $\begin{array}{l}\text { GOLD IV } \\
(n=I 7)\end{array}$ & $P$ value* \\
\hline Age, $y r$ & $62 \pm 6$ & $65 \pm 7$ & $65 \pm 7$ & NS \\
\hline $\mathrm{FEV}_{1}, \%$ & $57 \pm 7.3$ & $40 \pm 5.6$ & $25 \pm 3.2$ & $<0.001$ \\
\hline $\mathrm{FEV}_{1} / \mathrm{FVC}, \%$ & $48 \pm 7.7$ & $39 \pm 6.5$ & $28 \pm 5$ & $<0.001$ \\
\hline $\mathrm{RV}, \%$ & $|4| \pm 28.5$ & $159 \pm 34.9$ & $189 \pm 35$ & $<0.001$ \\
\hline FRC, \% & $136 \pm 18.8$ & $148 \pm 26$ & $169 \pm 30$ & $<0.001$ \\
\hline TLC, \% & $109 \pm 10.6$ & $109 \pm 17.4$ & $112 \pm 16$ & NS \\
\hline Dyspnea, mMRC & $2.3 \pm 0.9$ & $2.2 \pm 0.7$ & $2.7 \pm I$ & NS \\
\hline $\mathrm{BMI}, \mathrm{kg} / \mathrm{m}^{2}$ & $29 \pm 3.8$ & $29 \pm 5.5$ & $27.8 \pm 5.5$ & NS \\
\hline PMS neck press, kg & $25 \pm 7$ & $24 \pm 7$ & $22 \pm 5$ & NS \\
\hline PMS chest pull, kg & $44 \pm 11$ & $41.7 \pm 9$ & $4 I \pm 6$ & NS \\
\hline PMS butterfly, kg & $19.5 \pm 6.6$ & $19.8 \pm 7.6$ & $17.5 \pm 5.4$ & NS \\
\hline PMS flexion, kg & $17.4 \pm 7.7$ & $17 \pm 4.7$ & $15.6 \pm 6.1$ & NS \\
\hline SWT distance, $\mathrm{m}$ & $39.5 \pm 11.7$ & $38.2 \pm 12.6$ & $40.4 \pm 10.4$ & NS \\
\hline SWT level & $7.8 \pm 2$ & $7.1 \pm 1$ & $5.7 \pm 1.7$ & 0.001 \\
\hline CPET power, watts & $76.3 \pm 27$ & $61 \pm 20.5$ & $44.7 \pm 20.4$ & $<0.001$ \\
\hline $\mathrm{VO}_{2} \max , \mathrm{mL} / \mathrm{min} / \mathrm{kg}$ & $17.2 \pm 2.9$ & $14 \pm 3.3$ & $12.5 \pm 3.7$ & $<0.001$ \\
\hline $\mathrm{VO}_{2} \max , \%$ & $62 \pm 11$ & $54 \pm 15.5$ & $46.6 \pm 13$ & 0.007 \\
\hline Emphysematous phenotype & $9(50 \%)$ & 13 (44.8\%) & $10(58.8 \%)$ & NS \\
\hline
\end{tabular}

Notes: *Calculated by ANOVA or chi-square tests. Data are expressed as means and standard deviations or as absolute and relative frequencies for each group.

Abbreviations: CPET, cardio-pulmonary exercise test; NS, not significant; mMRC, modified Medical Research Council scale; BMI, body mass index; PMS, peripheral muscle strength; SWT, shuttle walking test; CPET, cardio-pulmonary exercise test; $\mathrm{VO}_{2}$ max, maximal oxygen uptake; FEV ${ }_{1}$, forced expiratory volume in the first second of expiration; FVC, forced vital capacity; TLC, total lung capacity; RV, residual volume; FRC, functional residual capacity.

Table 4 Clinical and functional characteristics of the 64 male study participants according to COPD phenotype

\begin{tabular}{|c|c|c|c|}
\hline Characteristics & $\begin{array}{l}\text { Non-emphysema } \\
(n=32)\end{array}$ & $\begin{array}{l}\text { Emphysema } \\
(n=32)\end{array}$ & $P$ value* \\
\hline $\mathrm{BMI}, \mathrm{kg} / \mathrm{cm}^{2}$ & $31.4 \pm 5.2$ & $26.5 \pm 3.5$ & $<0.001$ \\
\hline FVC, \% & $78.3 \pm 12.9$ & $90.8 \pm 16.1$ & 0.002 \\
\hline $\mathrm{FEV}_{1}, \%$ & $43.3 \pm 10.9$ & $41.2 \pm 13.9$ & NS \\
\hline $\mathrm{FEV}_{\mathrm{I}} / \mathrm{FVC}, \%$ & $43.2 \pm 9.6$ & $36.9 \pm 8.5$ & 0.006 \\
\hline $\mathrm{RV}, \%$ & $152 \pm 28$ & $165 \pm 45$ & NS \\
\hline FRC, \% & $138 \pm 2 \mid$ & $158 \pm 29$ & 0.006 \\
\hline TLC, \% & $104 \pm 12$ & $117 \pm 16$ & 0.003 \\
\hline $\mathrm{KCO}, \%$ & $103 \pm 25$ & $65 \pm 14$ & $<0.001$ \\
\hline $\mathrm{PaCO}_{2}, \mathrm{mmHg}$ & $44 \pm 5.6$ & $40 \pm 4.9$ & 0.013 \\
\hline $\mathrm{PaO}_{2}, \mathrm{mmHg}$ & $70.6 \pm 10.6$ & $73.1 \pm 11.9$ & NS \\
\hline PMS neck press, kg & $25 \pm 7.5$ & $23 \pm 5$ & NS \\
\hline PMS chest pull, kg & $44.4 \pm 10.2$ & $39.9 \pm 7.1$ & 0.048 \\
\hline PMS butterfly, kg & $21.3 \pm 8.2$ & $16.9 \pm 3.9$ & 0.010 \\
\hline PMS flexion, kg & $18 \pm 7$ & $15.3 \pm 4.3$ & 0.089 \\
\hline PMS extension, kg & $41.6 \pm 12.9$ & $36 \pm 9.9$ & 0.076 \\
\hline SWT distance, $\mathrm{m}$ & $401 \pm 142$ & $359 \pm 153$ & NS \\
\hline CPET power, watts & $67.9 \pm 26.7$ & $54 \pm 21.5$ & 0.026 \\
\hline $\mathrm{VO}_{2} \max , \mathrm{mL} / \mathrm{min} / \mathrm{kg}$ & $14.8 \pm 3.9$ & $14.3 \pm 3.6$ & NS \\
\hline $\mathrm{VO}_{2} \max , \%$ & $57 \pm 15.8$ & $51.5 \pm 13.2$ & NS \\
\hline
\end{tabular}

Notes: *Calculated by Student's t-test. Data are expressed as means and standard deviations.

Abbreviations: CPET, cardio-pulmonary exercise test; NS, not significant; mMRC, modified Medical Research Council scale; BMI, body mass index; CRDQ, chronic respiratory disease questionnaire; PMS, peripheral muscle strength; SWT, shuttle walking test; CPET, cardio-pulmonary exercise test; VO ${ }_{2}$ max, maximal oxygen uptake; FEV ${ }_{1}$, forced expiratory volume in the first second of expiration; FVC, forced vital capacity; TLC, total lung capacity; RV, residual volume; FRC, functional residual capacity; PaCO ${ }_{2}$, arterial carbon dioxide partial pressure; $\mathrm{PaO}_{2}$, arterial oxygen partial pressure at rest. 


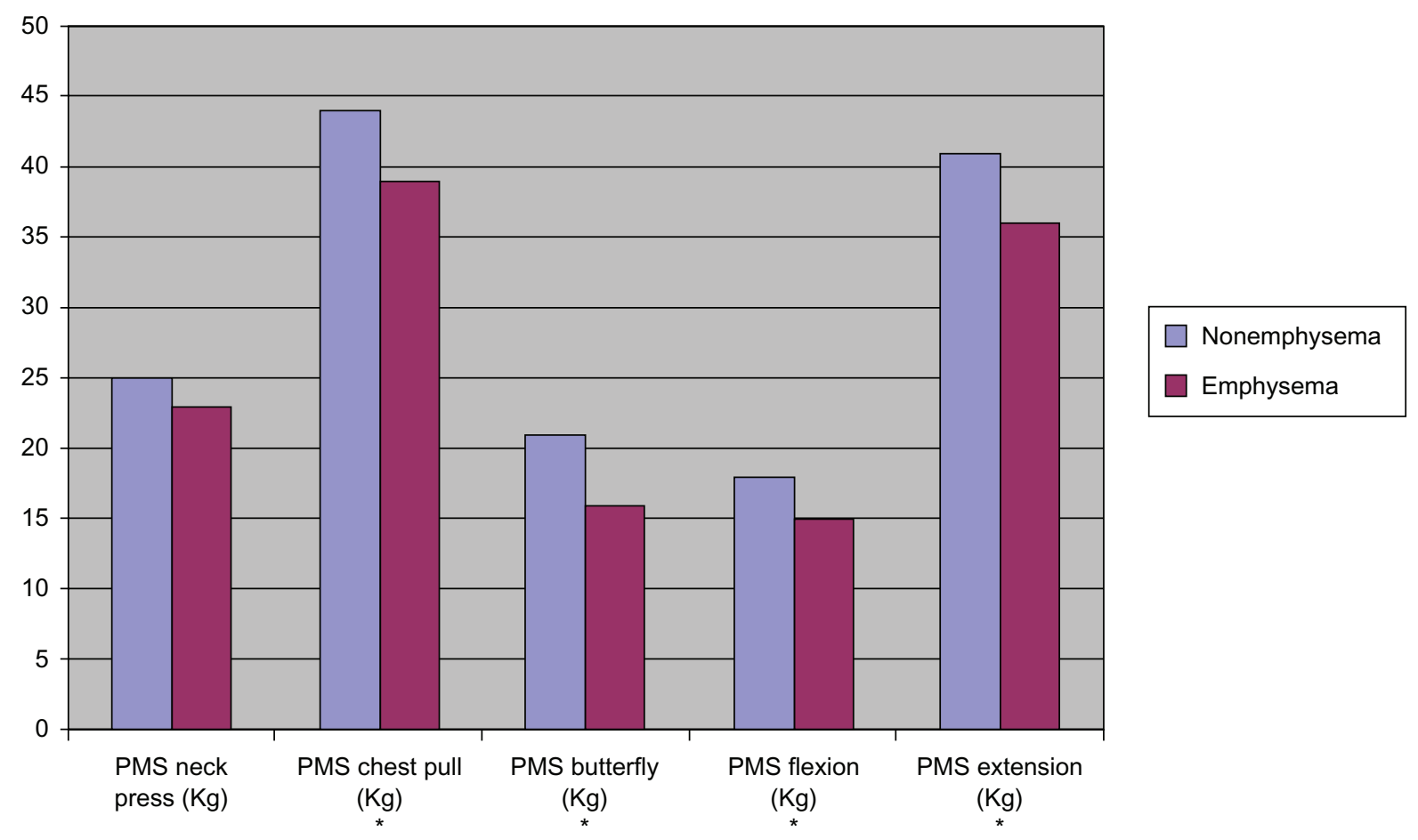

Figure I Differences in peripheral muscle strength between emphysema and nonemphysema patients.

Note: *Statistically significant.

Abbreviation: PMS, peripheral muscle strength.

lower $\mathrm{FEV}_{1} / \mathrm{FVC}$ ratio, and higher FVC, FRC, and TLC than nonemphysematous patients. Equally, BMI was significantly lower in emphysematous patients. However these parameters did not vary by GOLD stages, which shows that they are related more to the grade of emphysema than to the grade of airway obstruction of the patients. In these subjects, the distance walked in the SWT was lower, which could be an expression of a greater affect on exercise capacity in emphysematous patients. This was confirmed in the maximum exercise capacity test, as emphysematous patients had lower CPET power.

Peripheral muscle weakness is commonly found in patients with COPD. Compared with normal subjects of

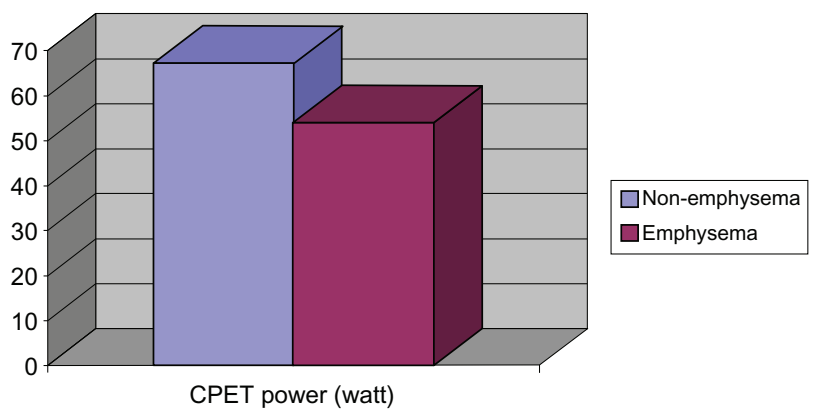

Figure 2 Differences in cardio-pulmonary exercise test power between emphysema and nonemphysema patients.

Abbreviation: CPET, cardio-pulmonary exercise test. similar age, the reduction in quadriceps strength averages $20 \%$ to $30 \%$ in patients with severe to moderate disease. ${ }^{42}$ In this study, PMS was significantly more impaired in emphysematous than in nonemphysematous patients in the majority of 1RM maneuvers. In COPD, there is a loss of muscle mass and a muscle fiber-type shift from type I to type II accompanied by reduced activities of enzymes involved in oxidative energy metabolism. ${ }^{43}$ These changes have been associated with disease severity and BMI, but it is unclear whether fiber type redistribution is comparable between the COPD subtypes emphysema and chronic bronchitis. ${ }^{44}$ These modifications might affect impairment of muscle function, which we found to be associated with the emphysematous phenotype. Among COPD patients, upper limb strength is in general relatively well preserved compared with the lower limbs. ${ }^{45}$ The uneven distribution of muscle weakness between upper and lower limbs could be related to differences in accustomed level of activity between the different muscle groups. In this study, we found significant differences according to COPD phenotypes in both upper and lower body strength.

Peripheral muscle abnormalities and lung hyperinflation may play a major role in the pathogenesis of exercise intolerance among COPD patients. ${ }^{46}$ Lung hyperinflation has been related to a systemic inflammatory response, as resistive 
breathing per se is an "immune challenge" for the body, elevating plasma cytokines and activating lymphocyte subpopulations. ${ }^{47}$ It also has been shown that inspiratory fraction as an index of increased lung volumes is an independent predictor of maximal exercise capacity in patients with COPD. ${ }^{48}$ Moreover, inflammatory markers play an important part in muscle dysfunction and exercise intolerance. ${ }^{49} \mathrm{We}$ have found a relationship between hyperinflation (total lung capacity and residual volume) and emphysematous patients, who have impaired exercise capacity. This could be due to the inflammation caused by hyperinflation, which is related to peripheral muscle dysfunction.

It is worth noting that the physical capacity parameters - including exercise capacity and PMS - are patient-centered measurements which significantly affect patient health status. ${ }^{50}$ Makita et $\mathrm{al}^{4}$ found that subjects with severe emphysema had poorer quality of life scores, evaluated using the St. George's Respiratory Questionnaire, than those without emphysema. In our study, however, we were unable to find an association between HRQL and severity of emphysema. In turn, a significant negative relationship was found between emphysema score and the mMRC dyspnea scale.

A limitation of the study is that we used visual scoring to assess emphysema severity rather than objective quantification. However, all HRCT images were thin-slice $(<2 \mathrm{~mm})$ and we carefully optimized the parameters for data analysis to obtain ideal images for assessment of emphysema. We were able to assess the overall percentage of emphysema and many investigators have demonstrated that a visual emphysema score for computer tomography images was highly correlated with objective volume-based computerized assessment., ${ }^{4,14}$ Moreover, the sample size was not calculated by what we cannot say that the results have not reached statistical significance are not due to a small sample size.

In summary, we have shown that compared with subjects with a nonemphysematous phenotype, subjects with an emphysematous phenotype have a different profile in terms of BMI, lung function, PMS, and exercise tolerance. The severity of emphysema is highly variable, even in patients with the same GOLD stage. Our results point to major differences among distinct phenotypes within COPD that should be taken into account in future studies.

\section{Acknowledgments}

This study was supported by grants from the Neumosur Foundation and the Consejería de Salud, Junta de Andalucía.

\section{Disclosure}

All the authors declare that they do not have a conflict of interest and that they do not have a financial relationship with a commercial entity that has an interest in the subject of this manuscript.

\section{References}

1. Global Initiative for Chronic Obstructive Lund Disease (GOLD) 2006. http://www.goldcopd.com/. Accessed July 21, 2007.

2. Hogg JC. Pathophysiology of airflow limitation in chronic obstructive pulmonary disease. Lancet. 2004;364:709-721.

3. Johnson MA, Woodcock, Rehahn M, Geddes DM. Are "pink puffers" more breathless than "blue bloaters"? Br Med J. 1983;15:286:179-182.

4. Makita H, Nasuhara Y, Nagai K, et al. Characterisation of phenotypes based on severity of emphysema in chronic obstructive pulmonary disease. Thorax. 2007;62:932-937.

5. Fujimoto K, Kitaguchi Y, Kubo K, Honda T. Clinical analysis of chronic obstructive pulmonary disease phenotypes classified using highresolution computed tomography. Respirology. 2006;11:731-740.

6. Kitaguchi Y, Fujimoto K, Kubo K, Honda T. Characteristics of COPD phenotypes classified according to the findings of HRCT. Respir Med. 2006; 100:1742-1752.

7. Boschetto P, Quintavalle S, Zeni E, et al. Association between markers of emphysema and more severe chronic obstructive pulmonary disease. Thorax. 2006;61:1037-1042.

8. Sin DD, Anthonisen NR, Soriano JB, Agustí AG. Mortality in COPD: role of comorbidities. Eur Respir J. 2006;28:1245-1257.

9. Celli BR, MacNee W. ATS/ERS Task Force. Standards for the diagnosis and treatment of patients with COPD: a summary of the ATS/ERS position paper. Eur Respir J. 2004;23:932-946.

10. García-Aymerich J, Lange P, Benet M, Schnohr P, Antó JM. Regular physical activity reduces hospital admission and mortality in chronic obstructive pulmonary disease: a population based cohort study. Thorax. 2006;61:772-778.

11. Oga T, Nishimura K, Tsukino M, Sato S, Hajiro T. Analysis of the factors related to mortality in chronic obstructive pulmonary disease. Role of exercise capacity and health status. Am J Respir Crit Care Med. 2003;167:544-549.

12. Swallow EB, Reyes D, Hopkinson NS, et al. Quadriceps strength predicts mortality in patients with moderate to severe chronic obstructive pulmonary disease. Thorax. 2007;62:115-120.

13. Soler-Cataluña JJ, Sánchez-Sánchez L, Martínez-García MA, et al. Mid-Arm muscle area is a better predictor of mortality tan body mass index in COPD. Chest. 2005;128:2108-2115.

14. Martinez FJ, Foster G, Curtis JL, et al. Predictors of mortality in patients with emphysema an sevre airflow obstruction. Am J Respir Crit Care Med. 2006;173:1326-1334.

15. American Thoracic Society; American College of Chest Physicians. ATS/ACCP Statement on cardiopulmonary exercise testing. Am J Respir Crit Care Med. 2003;167:211-277.

16. Celli BR, Cote CG, Marin JM, et al. The body-mass index, airflow obstruction, dyspnea, and exercise capacity index in chronic obstructive pulmonary disease. $N$ Engl J Med. 2004;350:1005-1012.

17. Elias Hernandez MT, Fernandez Guerra J, Toral Marin J, Ortega Ruiz F, Sanchez Riera H, Montemayor Rubio T. Reproducibility of a shuttle walking test in patients with chronic obstructive pulmonary disease. Arch Bronconeumol. 1997;33:64-68.

18. Mahler D, Wells C. Evaluation of clinical methods for rating dyspnea. Chest. 1988;93:580-586.

19. Recomendaciones de la Sociedad Española de Neumología y Cirugía Torácica (SEPAR). Normativa para la espirometría forzada. Barcelona: Ed. Doyma; 1985.

20. Standardization of spirometry -1987 update. Statement of the American Thoracic Society. Am Rev Respir Dis. 1987;136:1285-1298. 
21. Goldman HI, Becklake MR. Respiratory function tests: normal values at median altitudes and the prediction of normal results. Am Rev Tuberc. 1959;79:457-467.

22. Recomendaciones SEPAR. Normativa sobre gasometría arterial. Barcelona: Ed. Doyma; 1987.

23. Guell R, Casan P, Sangenis M, et al. The Spanish translation and evaluation of a quality-of-life questionnaire in patients with chronic obstructive pulmonary disease. Arch Bronconeumol. 1995;31:202-210.

24. Lillegrad WA, Terrio JD. Aprpropriate strength training. Med Clin North Am. 1994;78:457-477.

25. Hamilton A, Killian K, Summers E, et al. Muscle strength, symptom intensity and exercise capacity in patients with cardiorespiratory disorders. Am J Respir Crit Care Med. 1995;152:2021-2031.

26. Singh SJ, Morgan MD, Scott S, Walters D, Hardman AE. Development of a shuttle walking test of disability in patients with chronic airways obstruction. Thorax. 1992;47:1019-1024.

27. ERS Task Force, Palange P, Ward SA, et al. Recommendations on the use of exercise testing in clinical practice. Eur Respir J. 2007;29:185-209.

28. Wasserman K, Hansen JE, Sue DY, et al. Principles of Exercise Testing and Interpretation. 11th edition. Philadelphia: Cea and Febiger, 1980.

29. Whipp BJ, Wagner PD, Agusti A. Determinants of the physiological systems responses to muscular exercise in helathy subjects. Eur Respir Mon. 2007;40:1-35.

30. Borg GA. Psychophysical bases of perceived exertion. Med Sci Sports Exerc. 1982;14:377-381.

31. Webb WR. Radiology of obstructive pulmonary disease. AJR Am J Roentgenol. 1997;169:637-647.

32. Goddard PR, Nicholson EM, Laszlo G, Watt I. Computed tomography in pulmonary emphysema. Clin Radiol. 1982;33:379-387.

33. Nakano Y, Muro S, Sakai H, et al. Computed tomographic measurements of airway dimensions and emphysema in smokers. Am J Respir Crit Care Med. 2000;162:1102-1108.

34. Carlson DJ, Ries AL, Kaplan RM. Prediction of maximum exercise tolerance in patients with COPD. Chest. 1991;100:307-311.

35. Nishimura K, Izumi T, Tsukino M, Oga T. Dyspnea is a better predictor of 5-year survival than airway obstruction in patients with COPD. Chest. 2002;121:1434-1440.

36. Soler-Cataluna JJ, Martinez-Garcia MA, Roman Sanchez P, Salcedo E, Navarro M, Ochando R. Severe acute exacerbations and mortality in patients with chronic obstructive pulmonary disease. Thorax. 2005;60:925-931.
37. Curtis JR, Patrick DL. The assessment of health status among patients with COPD. Eur Respir J Suppl. 2003;41:36s-45s.

38. Tashkin DP. The role of patient-centered outcomes in the course of chronic obstructive pulmonary disease: how long-term studies contribute to our understanding. Am J Med. 2006;119:63-72.

39. Kim WD, Ling SH, Coxson HO, et al. The association between small airway obstruction and emphysema phenotypes in COPD. Chest. 2007;131:1372-1378.

40. Izquierdo JL, Almonacid C, Parra T, Perez J. Systemic and lung inflammation in 2 phenotypes of chronic obstructive pulmonary disease. Arch Bronconeumol. 2006;42:332-337.

41. Fletcher CM, Jone NL, Burrows B, Niden AH. American emphysema and British bronchitis. A standardized comparative study. Am Rev Respir Dis. 1964;90:1-13.

42. Hamilton AL, Killian KJ, Summers E, Jones NL. Muscle strength, symptom intensity, and exercise capacity in patients with cardiorespiratory disorders. Am J Respir Crit Care Med. 1995;152:2021-2031.

43. Couillard A, Prefaut C. From muscle disuse to myopathy in COPD: potential contribution of oxidative stress. Eur Respir J. 2005;26:703-719.

44. Gosker HR, Zeegers MP, Wouters EF, Schols AM. Muscle fibre type shifting in the vastus lateralis of patients with COPD is associated with disease severity: a systematic review and meta-analysis. Thorax. 2007;62:944-949.

45. Bernard S, LeBlanc P, Whittom F, et al. Peripheral muscle weakness in patients with chronic obstructive pulmonary disease. Am J Respir Crit Care Med. 1998;158:629-634.

46. Pepin V, Saey D, Laviolette L, Maltais F. Exercise capacity in chronic obstructive pulmonary disease: mechanisms of limitation. COPD. 2007;4:195-204.

47. Vassilakopoulos T, Roussos C, Zakynthinos S. The immune response to resistive breathing. Eur Respir J. 2004;24:1033-1043.

48. Albuquerque A, Nery L, Villaca D, et al. Inspiratory fraction and exercise impairment in COPD patients GOLD stages II-III. Eur Respir J. 2006;28:939-944.

49. Yende S, Waterer GW, Tolley EA, et al. Inflamtory markers are associated with ventilatory limitation and muscle dysfunction in obstructive lung disease in well functioning elderly subjects. Thorax. 2006;61:10-16.

50. Toral Marin J, Ortega F, Cejudo P, Elias T, Sanchez H, Montemayor T. Peripheral muscle strength in stable COPD patients: correlation with respiratory function variables and quality of life. Arch Bronconeumol. $1999 ; 35: 117-121$
International Journal of COPD

\section{Publish your work in this journal}

The International Journal of COPD is an international, peer-reviewed journal of therapeutics and pharmacology focusing on concise rapid reporting of clinical studies and reviews in COPD. Special focus is given to the pathophysiological processes underlying the disease, intervention programs, patient focused education, and self management protocols.

\section{Dovepress}

This journal is indexed on PubMed Central, MedLine and CAS. The manuscript management system is completely online and includes a very quick and fair peer-review system, which is all easy to use. Visit http://www.dovepress.com/testimonials.php to read real quotes from published authors. 